Service de Pneumologie, Hôpital Antoine Béclère, Clamart, France

Correspondence to: Dr Marina Karmochkine, Service de Médecine Interne, CHU PitiéSalpêtrière, 47/83, Boulevard de l'Hôpital, 75651 Paris Cedex 13, France.

1 Asherson R A, Higenbottam T W, Dinh Xuan A T, Khamashta $M$ A, Hughes $G R$ V. Pulmonary hypertension in a lupus clinic: experience with twenty-four patients. $\mathcal{f}$ Rheumatol 1990; 17: 1292-8.

2 Winslow T M, Ossipov M A, Fazio G P, Simonson J S, Redberg R F, Schiller N B. Five-year follow-up study of the prevalence and progression of pulmonary hypertension in systemic lupus erythematosus. Am Heart $\mathcal{f}$ 1995; 129: 510-15.

3 D'Alonzo G E, Barst R J, Ayres S M, et al. Survival in patients with primary pulmonary hypertension: results from a national prospective registry. Ann Intern Med 1991; 115: 343-9.

4 Dahl M, Chalmers A, Wade J, Calverley D, Munt B. Ten year survival of a patient with Munt $B$. Ten year survival of a patient with dvanced pulmonary hypertension and mixed connective tissue disease treated with 1992; 19: 1807-9 therapy. $\mathcal{F}$ Rheumatol 1992; 19: 1807-9.

5 Goupille P, Fauchier L, Babuty D, Fauchier J, Valat J P. Precapillary pulmonary hypertension dramatically improved with high doses of corticosteroids during systemic lupus erythematosus. f Rheumatol 1994; 21: 1976-7.

6 Groen H, Bootsma H, Postma D S, Kallenberg C G M. Primary pulmonary hypertension in a patient with systemic lupus erythematosus: partial improvement with cyclophosphamide. partial improvement with cycloph

\section{Antibodies to ribosomal P proteins and hepatic damage in undifferentiated CTD}

Ribosomal antibodies were first detected by immunofluorescence in the serum samples of a few patients with systemic lupus erythematosus (SLE) in 1974 by Homberg et al. Presently, it is well known that most ribosomal antibodies recognise a conserved sequence of 22 aa at the carboxy terminus of three ribosomal phosphoproteins $\mathrm{P} 0, \mathrm{P} 1$, and P2 with molecular weights 38,19 , and 17 $\mathrm{kDa}$ respectively (antibodies to ribosomal $\mathrm{P}$ proteins). ${ }^{2}$ These antibodies have been described in about $10 \%$ of patients with SLE and their presence in serum is considered a marker of this disease. Various reports have shown an association between ribosomal antibodies and the development of lupus psychosis, ${ }^{3}{ }^{4}$ whereas others found a correlation with lupus activity. ${ }^{5}$ Recently, an association between antibodies to ribosomal $P$ proteins and liver or renal complications, or both, in SLE has been suggested. ${ }^{67} \mathrm{We}$ would like to comment on an interesting case in which a relation between the development of liver disease and the titres of antibodies to ribosomal $\mathbf{P}$ proteins was found in a patient with undifferentiated connective tissue disease.

In March 1992 a 9 year old girl was referred to Asturias Central Hospital with high fever, polyarthritis, oral ulcers, Raynaud's phenomenon, generalised hand swelling, and conjunctivitis. Laboratory studies showed a normal total and differential white cell count, an erythrocyte sedimentation rate of $88 \mathrm{~mm} / 1 \mathrm{st} \mathrm{h}$, and serum $\mathrm{C}$ reactive protein of $5.1 \mathrm{mg} / 1$ (normal values (NV) $<6 \mathrm{mg} / \mathrm{l}$ ). Blood chemistry showed slightly raised levels of the liver enzymes aspartate aminotransferase (AST) and alanine aminotransferase (ALT) (fig 1) Immunological studies disclosed increased levels of serum IgG to $24 \cdot 4 \mathrm{~g} / 1$ (NV 5.6-17.6 $\mathrm{g} / \mathrm{l})$, a rheumatoid factor test of $126 \mathrm{IU} / \mathrm{ml}$ (NV $<30 \mathrm{IU} / \mathrm{ml}$ ), and normal complement levels. Immunofluorescence on Hep-2 cells showed positive staining of the cytoplasm and nucleoli; no other nuclear staining patterns were observed. The patient's serum strongly stained the cytoplasm of the chief cells of rat stomach, which is characteristic of the presence of ribosomal antibodies. The serum was titrated for the presence of ribosomal and nucleolar antibodies on rat tissue sections (liver, kidney, and stomach) (fig 1). At the starting dilution (1/40) all normal serum samples were negative. The Western blot test, using rat ribosomes as a source of antigen, disclosed the presence of antibodies reacting with a $38 \mathrm{kDa}$ ribosomal $\mathrm{P0}$ protein (ribosomal antibodies) (fig 2). Tests for other autoantibodies (dsDNA, SS-A, SS-B, Sm, and $n R N P$ ) were negative.

Despite the presence of antibodies to ribosomal $\mathbf{P}$ protein, which is considered as a marker of SLE, the diagnosis was undifferentiated connective tissue disease because the patient did not fulfil the American Rheumatism Association criteria for the diagnosis of SLE. She was treated with prednisolone $(20 \mathrm{mg} /$ day $)$. The acute manifestations resolved rapidly, and the patient left hospital three weeks later in a good condition. The dose of prednisolone was tapered gradually.

In February 1993, while the patient was receiving a daily dose of $2 \mathrm{mg}$ of prednisolone and $500 \mathrm{mg}$ of the non-steroidal antiinflammatory drug naproxen, a high increase in the seric concentration of the liver enzymes was observed (AST $334 \mathrm{U} / \mathrm{l}$, ALT $438 \mathrm{U} / \mathrm{l}$ $\mathrm{NV}<31 \mathrm{U} / \mathrm{l}$ for both enzymes). She had no hepatomegaly and serological tests for the Epstein-Barr virus, cytomegalovirus, and viral hepatitis were all negative. The increased liver enzyme levels were accompanied by a parallel increase in the titres of cytoplasmic and nucleolar antibodies. Owing

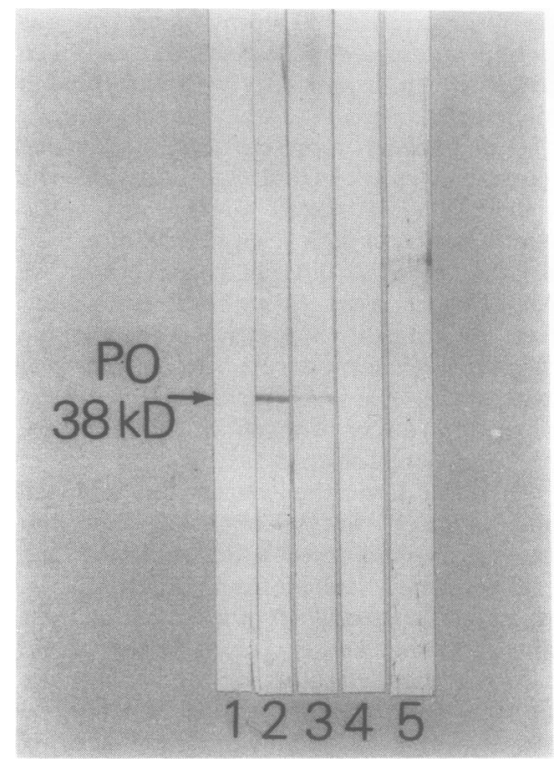

Figure 2 Recognition of antibodies against $P O$ ribosomal protein by immunoblotting. Lane $1=$ negative control serum; lanes 2 and $3=$ samples obtained from the patient in February 1993 and fuly 1995, respectively; lanes 4 and $5=$ samples containing mitochondrial antibodies.

to the possibility of drug induced liver damage, naproxen was discontinued and the dose of steroids reduced to $1 \mathrm{mg}$ on alternate days. However, the levels of liver enzymes and the titres of ribosomal antibodies and nucleolar antibodies remained abnormally high.

In April 1994 the patient was readmitted with an acute episode of severe asymmetrical polyarthritis. High dose prednisolone treatment was reintroduced $(0.75 \mathrm{mg} / \mathrm{kg}$ daily), and treatment with antimalarial drugs (3 $\mathrm{mg} / \mathrm{kg}$ daily) was started. Interestingly, despite the relapsing of her articular process the titre of autoantibodies decreased as well as the levels of liver enzymes, which normalised by June 1994. In September 1994
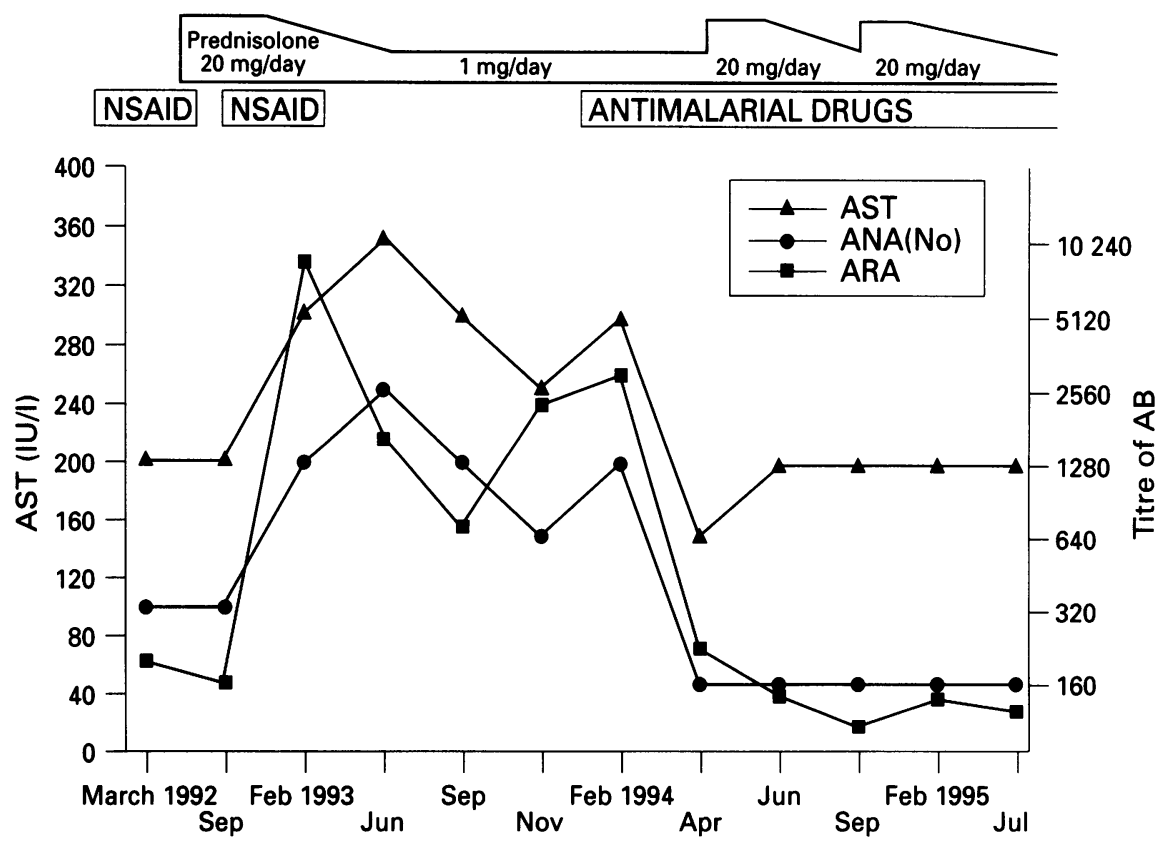

Figure 1 Correlation between seric concentration of liver enzymes and titres of ribosomal antibodies. $A S T=$ aspartate aminotransferase; $A N A(N o)=$ antinucleolar antibodies. $A R A=$ antiribosomal antibodies. Alanine aminotransferase levels ran parallel to those of AST (data not shown). 
the patient relapsed, developing oral and genital ulcers, again requiring treatment in hospital. However, the seric concentration of liver enzymes remained normal and the titre of antibodies did not increase. She received topical treatment and the dose of steroids was increased to $12 \mathrm{mg} /$ day. Three weeks later she was discharged from hospital and, at present, remains clinically stable.

In the present report a correlation between the titre of antibodies to ribosomal $\mathrm{P}$ proteins and the development of hepatic disease was seen. The levels of liver enzymes increased and decreased in parallel with the titres of ribosomal antibodies. Correlation between the titres of autoantibodies and other clinical manifestations was not found as the titres remained unchanged despite two acute episodes with important articular and dermatological complications. We do not have a definitive explanation of the relation between hepatic disease and the presence of ribosomal antibodies. However, it has recently been shown that these antibodies may bind to liver membranes in cell cultures. It may be, therefore, that these autoantibodies cause hepatopathy by binding in vivo to certain proteins in the hepatocyte membrane. Further studies will help to confirm this suggestion.
JUAN CARLOS TORRE Department of Physiotherapy, Universidad de Oviedo Spain

LOURDES MOZO

CARMEN GUTIÉRREZ

Department of Immunology, Department of Immunology,
Hospital Central de Asturias, Universidad de Oviedo, Spain

EDUARDO RAMOS Department of Pediatry, Hospital Central de Asturias, Oviedo, Spain

Correspondence to: Dr Carmen Gutiérrez, Department of Immunology, Hospital Central de Asturias, Julián Clavería s/n, 33006 Oviedo, Spain.

1 Homberg J C, Rizzetto M, Doniach D. Ribosomal antibodies detected by immunofluorescence in systemic lupus erythematosu and other collagenoses. Clin Exp Immuno 1974; 17: 617-28.

2 Elkon K B, Parnassa A P, Foster C L. Lupus autoantibodies target ribosomal $\mathrm{P}$ proteins. $\mathcal{J}$ Exp Med 1985; 162: 459-71.

3 Bonfa E, Golombek S J, Kaufman L D, et al. Association between lupus psychosis and anti-ribosomal $\mathrm{P}$ protein antibodies. $N$ Engl Med 1987; 317: 265-71.

4 Schneebaum A B, Singleton J D, West S G, et al. Association of psychiatric manifestations with antibodies to ribosomal $P$ proteins in with antibodies to ribosomal P proteins in 1991; 90: 54-62.
5 Sato $\mathrm{K}$ Uchiumi $\mathrm{T}$, Ozawa $\mathrm{T}$, et al. Autoantibodies against ribosomal proteins found with high frequency in patients with systemic lupus erythematosus. $\mathcal{f}$ Rheumato 1991; 18: 1681-4.

6 Koren E, Schnitz W, Reichlin M. Concomitan development of chronic active hepatitis and antibodies to ribosomal $\mathrm{P}$ proteins in a patien with systemic lupus erythematosus. Arthritis Rheum 1993; 36: 1325-8.

7 Hulsey M, Goldstein R, Scully L, Surbeck W, Reichlin $M$ Anti-ribs Reichlin $M$. Anti-ribosomal $P$ antibodies in systemic lupus erythematosus: a casecontrol study correlating hepatic and renal disease. C 74: 252-6.

8 Koren E, Reichlin M W, Koscec M, Fugate R D Reichlin M. Autoantibodies to the ribosomal $P$ proteins react with a plasma membranerelated target on human cells. $\mathcal{F}$ Clin Invest 1992; 89: 1236-41.

\section{Correction}

Can methotrexate be used as a steroid sparing agent in the treatment of polymyalgia rheumatica and giant cell arteritis?

van der Veen et al. (Ann Rheum Dis 1996; 55: 218-24)

It is regretted that an incorrect affiliation was given for Dr H J Dinant, who is rheumatologist at the Jan van Breemen Instituut, Amsterdam. 
1 Tyndall A, Gratwohl A. Haemopoietic stem and progenitor cells in the treatment of severe progenitor cells in the treatment of severe 55:149-51.

2 Jacobs P, Vincent MD, Martell RW. Prolonged remission of severe refractory rheumatoid arthritis following allogenic bone marrow transplantation for drug induced aplastic anaemia. Bone Marrow Transpl 1986;1:237-9.

3 Lowenthal RM, Duhlen ML, Atkinson K, Biggs JC. Apparent cure of rheumatoid arthritis by bone marrow transplantation. $f$ Rheumatol 1993;20:137-40.

4 Brugger W, Heimfeld S, Berenson RJ, Mertelsmann $R$, Kanz $L$. Reconstitution of haematopoiesis after high dose chemotherapy by opoiesis after high dose chemotherapy by autologous progenitor cells gen

5 Marmont AM, Tyndall A, Gratwohl A, Vischer Marmont AM, Tyndall A, Gratwohl A, Vischer
T. Haemopoietic precursor-cell transplants for T. Haemopoietic precursor-cell transplants for
autoimmune diseases. Lancet 1995;345:978.

\section{The association between fibromyalgia and carpal tunnel syndrome in the general population}

Fibromyalgia and carpal tunnel syndrome are common diseases in adult women. Their prevalences in the whole population are $2 \%^{1}$ and $9.2 \%,{ }^{2}$, respectively. Recently, a study performed in northern Spain has suggested that the two conditions are often associated, with 33 of 206 outpatients with fibromyalgia showing evidence of carpal tunnel syndrome. $^{3}$ This $16 \%$ prevalence for the association is higher than that observed for carpal tunnel syndrome alone and suggests that common underlying mechanisms are at work. However, the study was done on patients referred to the clinic for fibromyalgia and no data are known about the occurrence of the association in the general population. During a survey on the prevalence of peripheral pain in an Italian population sample, we came across several patients with fibromyalgia or carpal tunnel syndrome and have studied the occurrence of the association between the two conditions.

A postal questionnaire ${ }^{4}$ was sent to 4456 subjects living in Chiavari, northern Italy, to investigate the presence of articular signs and symptoms. Individuals were asked to report if they had any joint pain or swelling for more than four continuous weeks and if they currently had joint pain or swelling, by indicating the relevant sites on a mannequin. In addition, they were asked to report the presence of morning stiffness lasting more than 30 minutes. This set of questions was originally developed by the ARC Epidemiology Unit in Manchester, United Kingdom ${ }^{4}$ and its primary goal was to detect prevalent cases of rheumatoid arthritis.

The diagnosis of fibromyalgia was based on the criteria suggested in 1990 by the American College of Rheumatology ${ }^{5}$, that is, widespread pain and the presence of tenderness in at least 11 of 18 sites (tender points).
The diagnosis of carpal tunnel syndrome was made on clinical grounds. It included (a) history of numbness, paraesthesia, and/or pain in the fingers innervated by the median nerve, and (b) positive Tinel sign or positive Phalen sign. Invasive tests, such as nerve conduction studies, were not performed in view of the epidemiological nature of the research.

After two mailings, 2440 out of 4456 subjects $(54.8 \%)$ returned the questionnaire. Of these, $182(7.5 \%)$ had joint pain and swelling in at least two joints. This group of patients was offered a clinical examination; 93 (51.1\%) agreed to be visited. Fibromyalgia was present in $21(22.6 \%)$ of these patients and carpal tunnel syndrome in $26(28 \%)$. Both conditions occurred simultaneously in nine patients $(9.7 \%)$ (table). The odds ratio for patients with any one of the conditions of showing the other one was $2.4 \quad(95 \%$ confidence interval 0.9 to 6.8 ). These fibromyalgia-carpal tunnel syndrome patients were all female, whereas $23.5 \%$ of patients with carpal tunnel syndrome were male. What is more, if only women with carpal tunnel syndrome or fibromyalgia are considered, nearly half of them also had the other disease. The mean number of tender points was obviously higher in patients with fibromyalgia than in those with carpal tunnel syndrome alone $(13.2 v 3.8 ; \mathrm{P}<0.001)$. Self reported joint swelling and early morning stiffness were similarly distributed in the three groups of patients.

Our data show that responders who reported a history of joint pain and swelling of peripheral joints were often affected by fibromyalgia or carpal tunnel syndrome. This study does not disclose the absolute prevalence of fibromyalgia and carpal tunnel syndrome because the questionnaire was intended for screening patients with possible rheumatoid arthritis and not those with fibromyalgia or carpal tunnel syndrome. However, in a pilot study, most of the outpatients with these conditions attending a rheumatological clinic answered positively to the questionnaire. We believe that patients with fibromyalgia reported articular involvement on the mannequin because they were unable to differentiate articular from extra-articular pain. In addition, they frequently overreported swelling. Patients with carpal tunnel syndrome as a rule complain of pain and numbness associated with a subjective sensation of swelling in the hands, especially in the morning. Both fibromyalgia and carpal tunnel syndrome are characterised by morning stiffness.

In addition, there is the possibility of a selection bias due to over-representation of patients with more severe conditions, since this subgroup is more likely to respond to questionnaires. A further limitation of this study was that the same observer performed the Tinel and Phalen tests and pressed tender points. Therefore, information bias cannot be excluded. Both biases would increase the strength of this association. Nevertheless we feel that the magnitude of the association between fibromyalgia and carpal tunnel syndrome in the general population showed by our study should prompt further investigation on possible similarities in the aetiopathogenic mechanisms at work in these conditions.

MARCO A CIMMINO MARIA PARISI GIANLUIGI MOGGIANA SILVANO ACCARDO

Cattedra di Reumatologia DIMI, Università di Genova, Viale Benedetto XV, 6, 16132 Genova,

1 Wolfe F, Ross K, Anderson J, Russel IJ, Herbert $\mathrm{L}$. The prevalence and characteristics of fibromyalgia in the general population. Arthriti Rheum 1995;38:19-28.

2 De Krom MCTFM, Knipschild PG, Kester ADM, Thus CT, Boekkoi PF, Spaans F. Carpal tunnel syndrome: prevalence in the general population. If Clin Epidemiol 1992; 45:373-6.

3 Perez-Ruiz F, Calabozo M, Alonso-Ruiz A, Herrero A, Ruiz-Lucea E, Otermin I High prevalence of undetected carpal tunnel synprevalence of undetected carpal tunnel syndrome in patients with fibromyal

MacGregor AJ, Riste LK, Hazes JMW, Silman MacGregor AJ, Riste LK, Hazes JMW, Silman
AJ. Low prevalence of rheumatoid arthritis in AJ. Low prevalence of rheumatoid arthritis in
Black-Caribbeans compared with Whites in Black-Caribbeans compared with Whites in innner city

5 Wolfe F, Smythe HA, Yunus MB, et al. The American College of Rheumatology 1990 criteria for the classification of fibromyalgia: report of the Multicenter Criteria Committee. Arthritis Rheum 1990;33:160-72.

\section{Correction}

In the paper by Torre et al in the August issue ("Antibodies to ribosomal $\mathbf{P}$ proteins ..., p 562), the authors' names were printed in the wrong order. The order should have been; J C Torre, L Mozo, A Suárez, E Ramos, C Gutiérrez.

Demographic and clinical characteristics of the patients, expressed as means and $95 \%$ confidence intervals (CI)

\begin{tabular}{llll}
\hline & Fibromyalgia & $\begin{array}{l}\text { Carpal tunnel } \\
\text { syndrome }\end{array}$ & Both \\
\hline Number & 12 & 17 & 9 \\
Men/women & $1 / 11$ & $4 / 13$ & $0 / 9$ \\
Mean age (years (SD)) & $58.7(15.5)$ & $51.8(14.6)$ & $51.3(12.9)$ \\
Mean number of tender points & $13.4(11.8-15)$ & $3.8(2.6-5.1)$ & $13(11.1-14.9)$ \\
Mean duration of morning stiffness (min) & $65.7(23.2-108.2)$ & $44.5(25.7-63.3)$ & $31.4(15.7-47.1)$ \\
$\begin{array}{l}\text { Mean number of joints reported as } \\
\quad \text { swollen }\end{array}$ & $5.8(3.5-8.1)$ & $3.8(2.9-4.7)$ & $4.9(2.3-7.5)$ \\
& & &
\end{tabular}

